\title{
Health Impact Assessment of Urban Development Project
}

\author{
Parisa Shojaei ${ }^{1}$, Masoud Karimlou ${ }^{1}$, Farahnaz Mohammadi ${ }^{1} \&$ Hosein Malekafzali ${ }^{2}$ \\ ${ }^{1}$ Social Determinants of Health Research Center, Welfare and Rehabilitation University of Medical \\ Science,Tehran, Iran \\ ${ }^{2}$ School of Public Health, Tehran University of Medical Sciences, Tehran, Iran \\ Correspondence: Masoud Karimlou, PhD of Biostatistics, Associated Professor, Social Determinant of Health \\ Research Center, University of Social Welfare \& Rehabilitation Sciences, Tehran, Iran. Tel: 98-21-221-80146. \\ E-mail: mkarimlo@yahoo.com
}

Received: September 29, 2015 Accepted: December 28, 2015 Online Published: January 31, 2016

doi:10.5539/gjhs.v8n9p224 URL: http://dx.doi.org/10.5539/gjhs.v8n9p224

\begin{abstract}
Background: Health impact assessment (HIA) has emerged to identify those activities and policies likely to have major impacts on the health of a population.

Method: In this research, qualitative method was applied to identifying health determinants that urban man made lake affect on them, formatting and weighing the hierarchy of the factors, calculating AHP, and Technique for Order Preference by Similarity to Ideal Solution (TOPSIS) method for decide and ranking alternatives.
\end{abstract}

Results: According to the results of the study, from the structural determinants point of view, the most positive effect of man-made lake was on Recreational services by $89.5 \%$ and the most negative one was on housing. According to intermediary determinants and general average, the most positive effect of lake was on physical activity and quality of air by $88.9 \%$ and the most negative one was on noise pollution by $46.7 \%$. Ultimately, considering the positive and negative effects of lake between constructing and not constructing the lake option, the construction option was selected.

Conclusion: There is substantial potential to improve public health by bringing decision makers' attention to the health consequences of their actions; city councilpersons, zoning commissioners, and other decision makers typically have little background in health.

Keywords: Health impact assessment, Analytic Hierarchy Process (AHP), Technique for Order Preference by Similarity to Ideal Solution (TOPSIS), urban, man made lake

\section{Introduction}

It has been proved that environmental and social factors such as community design, land use, transportation systems and so on, have a great impact on public health, but there are no sufficient sophisticated health officials or urban planners who have been trained in this field (Azapagic et al., 2013). Generally a health impact assessment (HIA) is defined as "a combination of procedures, methods, and tools by which a policy, program, or project may be judged in terms of its potential effects on the health of a population, and the distribution of those effects within the population" (Ardell, 1969; Galea, 2002; Dannenberg et al., 2006). Although social determinants and multilevel perspectives are not exclusively urban, they clearly define urban characteristics of cities such as size, density, diversity, and complexity (Vlahov et al., 2007).

The objectives of constructing Man-made Lakes can be noted: hydropower generation, improvement of navigation, flood control, irrigation, recreation, and fish culture (Brown \& Deom, 1973). According to Scotland definition, Man-made Lakes and their surroundings are parts of green spaces and open space reservation (2008). It has been proved that, green spaces increase health promotion by encouraging physical activity and walking, reducing air and noise pollution and increasing social contact (Kihal-Talantikite et al., 2013). In world, several studies have been conducted with the main focus on evaluation of health effects of urban projects, but few of them are area of Man-made Lakes. Development-projects in Iran are not health-oriented. In other words, in national development plans health promotion is treated as a side subject like other economic, cultural, social indicators and so on. According to Ministry of Health and Medical Education mission to health promotion and promoting health equity (which is the main priority in Islamic Republic of Iran's health system), and also 
approval of the seventh session of the Supreme Council of Health and Food security of the country and paragraph B of 36th clause of the Fifth Economic, Social and Cultural Development Plan of Iran, is charged to prepare national standard for large developments projects (Biffi et al., 2011). Constructing Man-made Lakes faces with many hazards in developing countries.In order to exploit the full potential of water resources and lakes, improvement and maintenance of their is needed to participation of all stakeholders. Therefore in addition to engineers, the participation of other health experts particularly biology, sociology and economy in the process of planning and implementation of development projects should be considered (Araoye, 2002).

One of these projects in Iran is to construct the biggest Man-made Lake. Chitgar Lake is a Man-made Lake located in Northwest, 22 of municipality of Tehran. The lake has an area of 130 acres and there is a land area of 120 acres recreational service in the vicinity of it. The south of the lake is located in the residential area of 22 of municipality of Tehran (2013). This lake consists of three islands, green spaces, Recreational spaces, sport and games. Although the main purpose of constructing this lake is to enhance the capacity of recreation and also tourist attraction, paying no attention to the health issues cause serious problems. Because of the reasons mentioned and the need to health assessment of urban projects, we decided to assess health impact of this man made lake that the early stage of its construction was done.

\section{Methods}

To conduct the appraisal phase, 4 steps were run. In step A, a Qualitative method for Extracting health determinants associated with urban Man-made Lakes is employed, step B is weighting and prioritizing of its determinants, step C ranks the alternatives by TOPSIS, and step D Combine AHP and TOPSIS to determine the rank of alternatives.

\subsection{A-Qualitative Method}

This qualitative study was designed and carried out with a content analysis approach. Data were collected through focus group discussions (FGDs) as well as individual interviews from September to March 2013 respectively. The focus group discussions were carried out with 2 expert group in 2 session: 1- Members from the Municipal District 22 that involved in the man made lake project with at least a bachelor's degree and 2second group Members from outside the municipal District 22 and experts in the field of health determinants and environment to avoid information bias with at least a bachelor's degree.

The focus group discussion was selected because this method has high ability to explore people's ideas, worries, attitudes and experiences of individuals regarding a specific subject matter (Barbour \& Kitzinger, 1998; Dahlgren, Emmelin et al., 2007). Individual interviews were done on 34 informants in three groups: 1- people living in the 22 District, 2-Members from the Municipal District 22 and 3-third group Members from outside the municipal District 22 Informants were selected using purposive sampling and data gathering process was continued until data saturation.

\subsection{Limitations}

The present study explains the opinion of the individuals in FGDs and individual interviews and for methodological reasons (qualitative approach) the results of this study can not be generalized to other situations.

\subsection{B-Using AHP to Analyze Priorities}

In this step, after analyzing content analysis methodology, a list of all health determinants associated with Man-made Lake was extracted out by the use of Open Code software. AHP is a multi-criteria decision-making (MCDM) methodology which was developed in 1970 decade by Thomas Saaty. Analyzing complex decisions is the main usage of it which helps decision-makers to prioritize alternatives and determine the optimal alternative using pair-wise comparison judgments. Moreover, to avoid bias decision-making and provide impartiality weighting criteria by multiple experts is undertaken (Dağdeviren et al., 2009). Nevertheless, how the problem is conceived and then modeled or structured is the most important part of decision making which has a considerable effect on the outcome. Prioritization includes eliciting judgments on response to question about the dominance of one element over another when compared with respect to a specific criterion or property (Tzeng \& Huang, 2011). The philosophy behind this methodology is that, indeed a judgment is developed using numerical comparisons between two elements (or inputs) of the model which have a common criterion. A square matrix is applied to represent the set of all such judgments, in which all elements are compared with themselves. Each judgment shows the dominance of an element in the criterion list (Greenspan, 2006). It is also possible to run a Pair-wise comparison by assigning an integer ranging from 1 to 9 or the mutual of such an integer to each cell of the matrix to calculate the relative importance of the factors that characterize the cell (Saaty, 1980). By the use of this scaling approach, the available values for the pair-wise comparisons belong to the following set of numbers: 
$(9,8,7,6,5,4,3,2,1,1 / 2,1 / 3,1 / 4,1 / 5,1 / 6,1 / 7,1 / 8,1 / 9)$ (Saaty, 1980). In addition, according to the assumption of AHP method, each of the factors under assessment should be independent of another.

Firstly, to execute hierarchical analysis a hierarchical tree with its aim, criterion, sub-criterion, and options was formed, and then in order to weigh all determinants extracted from qualitative method, they were put in a checklist in the form of a pair-wise comparisons matrix. In this checklist that was designed in the form of a matrix, rows and columns consist of 28 determinants (Income, Physical and Social Development of Children, Culture, Physical Activity, Education, Quality of Life, Job, Nutrition, Limitation of available resources, Unhealthy Behavior, Traffic, Unintentional Injuries, Ethnicity, Pathogenesis, Tourism, Air Quality, Region Popularity, Mental Health, Recreational Services, Aesthetic, political participation, Social Capital, Spirituality, Weather Changes, Housing, Noise Pollution, Social Security, Environmental Health) that were extracted by qualitative method. In the next step, run a Pair-wise comparison by assigning an integer ranging from 1 to 9 or the mutual of such an integer to each cell of the matrix to calculate the relative importance of the factors using Saaty method. So weights were assigned to each of them by the same participants who have participated in the interviews (experts of second group and third group). After completing checklists, by the use of geometric mean comparative tables of each respondent were jointed together. The main reason for using geometric mean is that, data created by pair-wise scales are in the form of ratio. Since the interview subjects which completed this matrix were two groups of experts, therefore after completing paired matrix, a geometric mean was computed for each group, and then by a team of experts on health determinants this geometric mean of two groups were evaluated. Finally, the review panel formed a matrix showed the overall mean, and the matrix for analysis and measurement of weights as raw data which was used into the Expert choice software.

\subsection{C- Using Technique for Order Preference by Similarity to Ideal Solution (TOPSIS) to Rank the Alternatives}

Technique for Order Preference by Similarity to Ideal Solution (TOPSIS) was represented by Yoon (1980) and Hwang and Yoon (1981), in order to solve multiple criteria decision-making (MCDM) problems based on the concept of Euclidian distance. In other words, it states that chosen alternative should have the shortest Euclidian distance from the positive ideal solution (PIS) and the farthest from the negative ideal solution (NIS) (Hwang and Yoon). This MCDM method is applied in different fields, particularly financial performance evaluation, location selection, company evaluation, supplier selection, tourism destination evaluation, selecting the most suitable machine, ranking the carrier alternatives. One of the main advantages of TOPSIS is that pair-wise comparisons are avoided (Tsaur 2011). The TOPSIS method is conducted in six steps as follows:

Step 1: Normalized decision matrix was computed. The normalized value $r_{i j}$ is calculated as follows:

$$
r_{i j}=x_{i j} \sqrt{\sum_{i-1}^{m} x_{i j}^{2}} \quad \mathrm{i}=1,2, \ldots, \mathrm{m} \text { and } \mathrm{j}=1,2, \ldots, \mathrm{n} .
$$

Step 2: Weighted normalized decision matrix was computed. The weighted normalized value $v_{i j}$ is calculated as follows:

$$
V_{i j}=r_{i, j} \times_{W_{j}} \mathrm{i}=1,2, \ldots, \mathrm{m} \text { and } \mathrm{j}=1,2, \ldots, \mathrm{n} .
$$

Where $w_{i}$ is the weight of the $j^{t h}$ attribute or criterion and $\sum_{j=1}^{n} w_{j}=1$.

Step 3: the ideal $\left(\mathrm{A}^{*}\right)$ and negative ideal $\left(\mathrm{A}^{-}\right)$solutions were determined.

$$
\begin{aligned}
& A^{*}=\left\{\left(\max _{i} v_{i j} \mid j \in C_{b}\right),\left(\min _{i} v_{i j} \mid j \in C_{c}\right)\right\}=\left\{v_{j}^{*} \mid j=1,2, \ldots, m\right\} \\
& A^{-}=\left\{\left(\min _{i} v_{i j} \mid j \in C_{b}\right),\left(\max _{i} v_{i j} \mid j \in C_{c}\right)\right\}=\left\{v_{j}^{-} \mid j=1,2, \ldots, m\right\}
\end{aligned}
$$

Step3: the separation measures using the m-dimensional Euclidean distance for each alternative from the positive ideal solution and the negative ideal solution were computed, respectively as follows:

$$
\begin{aligned}
S_{i}^{*} & =\sqrt{\sum_{j=1}^{m}\left(V_{i j}-V_{j}^{*}\right)^{2}, j=1,2, \ldots, m} \\
S_{i}^{-} & =\sqrt{\sum_{j=1}^{m}\left(V_{i j}-V_{j}^{-}\right)^{2}, j=1,2, \ldots, m}
\end{aligned}
$$

Step 5: the relative closeness to the ideal solution was computed. The relative closeness of the alternative $\left(\mathrm{A}_{\mathrm{i}}\right)$ with respect to $\left(\mathrm{A}^{*}\right)$ is defined as follows: 


$$
R C_{i}^{*}=\frac{d_{i}^{-}}{d_{i}^{*}+d_{i}^{-}}, i=1,2, \ldots, m
$$

Step 6: Rank the preference order (Wu and Chuang 2013).

\section{$D$ - Combining AHP and TOPSIS to determine the rank of alternatives}

In order to analyze the data, AHP and TOPSIS methodologies were conducted to rank alternatives. Fig 1 illustrates the steps of the proposed methods.

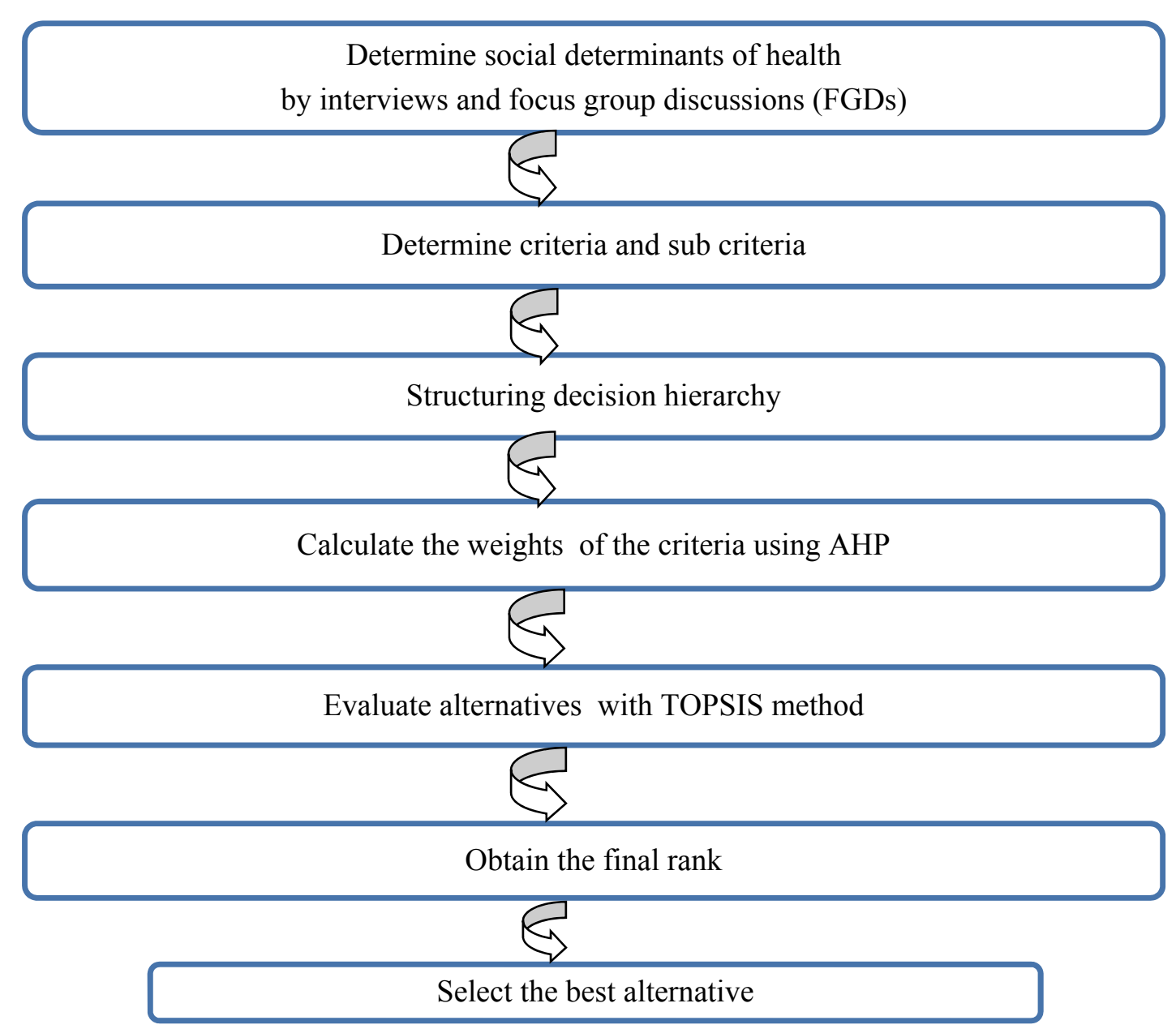

Figure 1. Steps of proposed method

\section{Results}

The present study was conducted in district 22 of Tehran municipality in 2013. Participants' mean age was obtained 30, they has been chosen among experts in urban development, environmental, water source, civil engineering, sociology, urbanization, and health determinants areas. Their education status was from $\mathrm{BS}$ to $\mathrm{PhD}$, and also four of them were resident of the region and the others were from other parts of the city. Applying Qualitative analysis of data, 301 codes have been provided. Moreover, conceptual framework structure developed by commission on social determinants of health as well as their subgroup was treated as data analysis matrix (Solar \& Irwin, 2010). Therefore two "structural" and "intermediary" groups were created, and in each stratum14 sub-groups were determined (Table 1). Then, in order to implement AHP process these 28 determinants were put in a checklist and were given to participants through focus group discussion and interviews. Thus, there was one goal, two criteria, and 28 sub-criteria with the addition of two options (construction and non-construction of Man-made Lake) to illustrate their hierarchies. 
Table 1. Structural and intermediary determinants of health associated with man made lake

\begin{tabular}{|c|c|c|c|}
\hline \multirow{14}{*}{$\begin{array}{l}\text { Structural } \\
\text { Determinants }\end{array}$} & Income & \multirow{14}{*}{$\begin{array}{l}\text { Intermediary } \\
\text { determinants }\end{array}$} & Physical and Social Development of Children \\
\hline & Culture & & Physical Activity \\
\hline & Education & & Quality of Life \\
\hline & Job & & Nutrition \\
\hline & Limitation of available resources & & Unhealthy Behavior \\
\hline & Traffic & & Unintentional Injuries \\
\hline & Ethnicity & & Pathogenesis \\
\hline & Tourism & & Air Quality \\
\hline & Region Popularity & & Mental Health \\
\hline & Recreational Services & & Aesthetic \\
\hline & political participation & & Social Capital \\
\hline & Spirituality & & Weather Changes \\
\hline & Housing & & Noise Pollution \\
\hline & Social Security & & Environmental Health \\
\hline
\end{tabular}

According to AHP approach and with regard to structural determinants criteria, for construction option maximum final weight (.895) belonged to recreational service sub-criteria and minimum weight (.638) for traffic. These sub-criteria for non-construction option were obtained maximum (.362) and minimum (.105), respectively.

For intermediary determinants in construction option, physical activity and air quality sub-criteria had maximum final weight (.889), and also pathogenesis sub-criterion had minimum final weight (.617). These sub-criteria for non-construction option were obtained maximum (.375) and minimum (.111), respectively.

Finally, to rank the alternative suppliers TOPSIS method was conducted. Moreover, the priority weights of alternative suppliers with respect to criteria, computed by AHP, can be applied as input of TOPSIS (Table 2). The weighted normalized decision matrix was also depicted in Table 3.

As it is illustrated in Table 4, the ranking of the alternatives is construction and non-construction depends on the $\mathrm{RCj}$ values.

Table 2. Input values of the TOPSIS analysis

\begin{tabular}{llll}
\hline Weight & & Construction & Non Construction \\
\hline 0.067 & Spirituality & 0.86 & 0.14 \\
101 & political participation & 0.863 & 0.132 \\
0.023 & Social Security & 0.681 & 0.319 \\
0.351 & Tourism & 0.889 & 0.111 \\
0.186 & Recreational Services & $0.895^{*}$ & 0.105 \\
0.245 & Region Popularity & 0.891 & 0.109 \\
0.027 & Traffic & $0.638^{*}$ & 0.362 \\
0.027 & Ethnicity & 0.804 & 0.196 \\
0.028 & Housing & 0.667 & 0.333 \\
0.085 & Job & 0.833 & 0.167 \\
0.486 & Income & 0.889 & 0.111 \\
0.146 & Education & 0.873 & 0.127 \\
0.183 & Culture & 0.857 & 0.143 \\
\hline
\end{tabular}




\begin{tabular}{llll}
\hline 0.045 & Limitation of available resources & 0.75 & 0.25 \\
0.028 & Unintentional Injuries & 0.786 & 0.214 \\
0.317 & Physical and Social Development of Children & 0.877 & 0.123 \\
0.069 & Nutrition & 0.783 & 0.217 \\
0.055 & Unhealthy Behavior & 0.75 & 0.25 \\
0.201 & Quality of Life & 0.857 & 0.143 \\
0.304 & Physical Activity & $0.889^{*}$ & 0.111 \\
0.027 & Pathogenesis & $0.617^{*}$ & 0.333 \\
0.219 & Mental Health & 0.896 & 0.131 \\
0.126 & Aesthetic & 0.857 & 0.143 \\
0.114 & Social Capital & 0.872 & 0.128 \\
0.029 & Noise Pollution & 0.667 & 0.333 \\
0.107 & Weather Changes & 0.836 & 0.164 \\
0.381 & Air Quality & $0.889^{*}$ & 0.111 \\
0.025 & Environmental Health & 0.625 & 0.375 \\
\hline
\end{tabular}

Table 3. Weighted evaluation for the supplier selection

\begin{tabular}{|c|c|c|c|c|c|}
\hline & Construction & Non Construction & & $\mathrm{A}^{*}$ & A- \\
\hline Spirituality & 0.056 & 0.001 & + & 0.056 & 0.001 \\
\hline political participation & 0.086 & 0.001 & + & 0.086 & 0.001 \\
\hline Social Security & 0.014 & 0.003 & + & 0.014 & 0.003 \\
\hline Tourism & 0.309 & 0.004 & + & 0.309 & 0.004 \\
\hline Recreational Services & 0.165 & 0.002 & + & 0.165 & 0.002 \\
\hline Region Popularity & 0.216 & 0.003 & + & 0.216 & 0.003 \\
\hline Traffic & 0.014 & 0.004 & - & 0.004 & 0.014 \\
\hline Ethnicity & 0.021 & 0.001 & + & 0.021 & 0.001 \\
\hline Housing & 0.016 & 0.004 & - & 0.004 & 0.016 \\
\hline Job & 0.069 & 0.001 & + & 0.069 & 0.001 \\
\hline Income & 0.429 & 0.008 & + & 0.429 & 0.008 \\
\hline Education & 0.126 & 0.002 & + & 0.126 & 0.002 \\
\hline Culture & 0.154 & 0.004 & + & 0.154 & 0.004 \\
\hline Limitation of available resources & 0.032 & 0.003 & - & 0.003 & 0.032 \\
\hline Unintentional Injuries Development of Children & 0.021 & 0.001 & - & 0.001 & 0.021 \\
\hline Physical and Social Development of Children & 0.275 & 0.005 & + & 0.275 & 0.005 \\
\hline Nutrition & 0.057 & 0.004 & + & 0.057 & 0.004 \\
\hline Unhealthy Behavior & 0.039 & 0.004 & - & 0.004 & 0.039 \\
\hline Quality of Life & 0.17 & 0.004 & + & 0.17 & 0.004 \\
\hline Physical Activity & 0.268 & 0.003 & + & 0.268 & 0.003 \\
\hline Pathogenesis & 0.014 & 0.004 & - & 0.004 & 0.014 \\
\hline Mental Health & 0.194 & 0.003 & + & 0.194 & 0.003 \\
\hline Aesthetic & 0.106 & 0.002 & + & 0.106 & 0.002 \\
\hline Social Capital & 0.098 & 0.002 & + & 0.098 & 0.002 \\
\hline
\end{tabular}




\begin{tabular}{llllll}
\hline Noise Pollution & 0.017 & 0.004 & - & 0.004 & 0.017 \\
Weather Changes & 0.087 & $0.003+$ & 0.087 & 0.003 \\
Air Quality & 0.336 & $0.004+$ & 0.336 & 0.004 \\
Environmental Health & 0.013 & $0.004+$ & 0.013 & 0.004 \\
\hline
\end{tabular}

Table 4. TOPSIS results

\begin{tabular}{llll}
\hline Alternatives & $\mathrm{di}+$ & $\mathrm{di}-$ & $\mathrm{RCi}$ \\
\hline Construction & 0.054 & 0.861 & 0.940 \\
Non construction & 0.861 & 0.054 & 0.059 \\
\hline
\end{tabular}

\section{Discussion}

There are many studies in the area of health impact assessment in different countries that have used quantitative and qualitative methods. Previous studies conducted with qualitative methods have used more of the interview and focus group discussion (Peters, 2002; Child Health Impact Assessment Working Group, 2005; Child Health Impact Assessment Working Group, 2006; Haigh and Scott-Samuel, 2006; University of California Berkeley Health Impact Group, 2007; Bhatia, 2010; Alameda County Public Health Department, 2013; Health Promotion Agency, 2013; Florida institute for health innovation, 2014). Qualitative studies can provide new theories about health that had not been studied about them. When stakeholders are offered in a participatory fashion, qualitative data collection analysis can be strong experiences for them. As one of the authors "most HIAs characterized impacts qualitatively; the use of quantitative analysis are deficient" (Wright, 2003; Avey, 2015).

In this study it has been showed that, constructing Man-made Lakes has significant effects on health determinants such as job, housing, income, recreational services and so on, which maximum weight belonged to recreational services, physical activity and air quality. Minimum weight also belonged to traffic and pathogenesis Our results proved that, this Man-made Lake and its surrounding Green Space enhance the possibility of physical activity and entertainment.

Water bodies have been applied widely in urban design i.e. as decorative element, space defining element, and also as a temperature-modifying element (Lang, 1994). Singh and Bhatnagar stated that Lakes have a significant portion of water in a pristine landscape where one goes for recreation. They are the sense of nature by providing outdoor activities such as boating, camping, fishing, swimming, bird watching, and etc. However, urban lakes demystified this picture. Mostly the main purpose of constructing urban parks is to facilitate physical activity which is particularly vital in urbanized countries (Brown et al., 2014). Although urban lakes are different from the common perception of lakes in general, they have both ecosystem functions and social values as well. They generate a wide range of ecosystem services, including, air filtration, noise reduction, micro climate regulation, rain water drainage, sewage treatment, recreational and cultural values (Singh \& Bhatnagar, 2012). According to the findings, constructing lakes and their surrounding green space cause traffic there, since they appear as tourist distinctions. Results from researches of South Carolina Institute of Medicine and Public Health (2013) illustrated that the probability of heavy traffic and therefore motor vehicles accidents increase drastically in the vicinity of parks. In addition, children and elderly are the most likely group to be involved in pedestrian related accidents (2013). Therefore, alongside aesthetic and recreational values which green spaces provide and make it of great of great concern to the community, urban mangers should be aware of problems following complaints from surrounding residents (Woodward, 2008). Diseases transmit through the water, due to the low hygiene, are another disadvantage of these facilities which cause a real concern as well. Results from Brown and Deom showed that, the prevalence of the infection is increased by the stagnant water in man-made lakes. Irrigation systems are also known as areas of Schistosomiasis in so far as they increase the availability of water and consequent human contact with it; it is now proved that the man-made lakes themselves produce the same deleterious effects (Brown \& Deom, 1973). Also in Iran, Swim in stagnant water such as a lake or marsh that the flow of water in it is not fast, Can be fertile ground for the growth of microbes, parasites and are thus susceptible to various diseases such as cerebral infection (2013). Therefore, since the advantages and disadvantages of Man-made Lakes on public health, their management needs cooperation with different organizations. Although the ecological and epidemiologic aspects of Man-made Lakes have been taken into account, the application and development of a health service structure to deal with present and prospective health hazards have been underestimated. Therefore, a responsible health institution, specifically a member of health ministry, should be 
established to deal with the area concerned from the inception of the project involving a man-made lake since the normal authority (the health ministry) has sometimes relinquished its duties when the responsibility for health along with other concerns of the project was placed under an ad hoc institution (the dam authority or valley authority). To make a comprehensive diagnosis of the situation and establish base lines, including a complete inventory of the existing health facilities, a public health administrator planner, assisted by a group of experts in the environmental fields of epidemiology, ecology, biology, sanitation, and any others that are required (Brown \& Deom, 1973). Woodward in a study on a Man-made Lake in a metropolis of Scotland found that, approximately $80 \%$ of constructed lakes studied have experienced or are experiencing management problems along with eutrophication issues. One or more of them were reported in half ( 23 of the 46) lakes (Woodward 2008). One of the main issues that urban designers face in making politically and economically astute proposals for projects is that, serious environmental problems accrue in designing to meet people's sociogenic needs. To keep the balance between the attainment of one goal and another in a way that not only is no further biogenic harm done but also future developments attain, guidelines and management manuals has been established that will shape environmental change (Majizat et al., n.d.).

To the inclusion of health in the decision-making process HIA approach can provide guidance for community leaders in the absence of good data on the effects of Man-made Lake on their citizenry health. To stakeholder involvement and acceptance of the final product, adherence to a transparent set of goals and objectives and an open and clear information-gathering and analysis process are vital (Borwick \& Pencharz, 2013). Moreover, HIA findings should be represented to decision- makers in concise, synthesized information to reach to a significant effect. Other interested audiences also include community members, journalists, advocacy organizations, and public health professionals.

As a conclusion, Due to the fact that urban populations need a different health profile and also the urban environment is substantially different from sub-urban or rural ones, urban health interventions differ from interventions in other settings. In addition, since decision-makers such as city council persons, zoning commissioners and so forth, typically have little background in health, substantial improvements occur in public health by training and bringing their attention to the health consequences of their actions (Maas et al., 2006).

\section{Acknowledgments}

This research is derived from the $\mathrm{PhD}$ thesis in specialized research social determinant of health approved by Research Council Session in Welfare and Rehabilitation Sciences University and the meeting of Ethics Committee of that university. We appreciate the Cooperation by honorable research deputy of university and honorable Municipality of District 22 of Tehran.

\section{Conflict of Interest}

The authors declare that there is no conflict of interests regarding the publication of this paper.

\section{References}

(2013). Brain infection as a result of swimming in stagnant water. Retrieved from http://www.momtaznews.com/

Araoye, P. (2002). Man-made lakes, ecological studies and conservation needs in Nigeria. Revista de biología tropical, 50(3-4), 857-864.

Ardell, D. B. (1969). Urban-planning-health-planning interrelationships. American Journal of Public Health and the Nations Health, 59(11), 2051-2055. http://dx.doi.org/10.2105/AJPH.59.11.2051

Avey, H. (2015). HIA Research: When is Qualitative Research Warranted?. Retrieved from http://www.humanimpact.org/from-the-hip-blog/hia-research-when-is-qualitative-research-warranted/\#sthas h.w6pxu9rq.dpuf

Azapagic, A., Chalabi, Z., Fletcher, T., Grundy, C., Jones, M., Leonardi, G., ... \& Vardoulakis, S. (2013). An integrated approach to assessing the environmental and health impacts of pollution in the urban environment: Methodology and a case study. Process Safety and Environmental Protection, 91(6), 508-520. http://dx.doi.org/10.1016/j.psep.2012.11.004

Barbour, R., \& Kitzinger, J. (1998). Developing focus group research: politics, theory and practice. Sage Publications Limited.

Bhatia, R. (2010). Protecting Health with Environmental Impact Assessment: A Case Study of San Francisco Land Use Decision Making. Tackling Health Inequities Through Public Health Practice: Theory to Action: 336. 
Biffi, M., Ziacchi, M. et al. (2011). How to truly value implantable cardioverter-defibrillators technology: Up-front cost or daily cost? International Journal of Technology Assessment in Health Care, 27(3), 201-206. http://dx.doi.org/10.1017/S0266462311000183

Borwick, V., \& Pencharz, M. (2013). Better environment, Better Health: A GLA guide for London's Boroughs, London Borough of City of London. London Greater London Authority.

Brown, A., \& Deom, J. (1973). Summary: Health aspects of man-made lakes. Geophysical Monograph Series, 17, 755-764. http://dx.doi.org/10.1029/GM017p0755

Brown, G., Schebella, M. F., \& Weber, D. (2014). Using participatory GIS to measure physical activity and urban park benefits. Landscape and Urban Planning, 121, 34-44. http://dx.doi.org/10.1016/j.landurbplan.2013.09.006

Child Health Impact Assessment Working Group. (2005). Affordable housing and child health: A child health impact assessment of the Massachusetts Rental Voucher Program. Retrieved from http://www.mlpforchildren.org/chia.aspx.

Child Health Impact Assessment Working Group. (2006). Unhealthy consequences: energy costs and child health - a child health impact assessment of energy costs and the low income home energy assistance program. Retrieved from http://www.mlpforchildren.org/chia.aspx

Dağdeviren, M., Yavuz, S., \& Kılınç, N. (2009). Weapon selection using the AHP and TOPSIS methods under fuzzy environment. Expert Systems with Applications, 36(4), 8143-8151. http://dx.doi.org/10.1016/j.eswa.2008.10.016

Dahlgren, L., Emmelin, M., \& Winkvist, A. (2007). Qualitative methodology for international public health. 2004. Print and media, Umeå University.

Dannenberg, A. L., Bhatia, R., Cole, B. L., Dora, C., Fielding, J. E., Kraft, K., ... \& Ross, C. L. (2006). Growing the field of health impact assessment in the United States: an agenda for research and practice. American Journal of Public Health, 96(2), 262-270. http://dx.doi.org/10.2105/AJPH.2005.069880

Florida Institute for Health Innovation. (2014). Minimizing the Health Effects of Climate Change in the South Florida Region. Florida, Florida institute for health innovation.

Galea, S. (2002). Urbanization, urbanicity, and health. Journal of Urban Health, 79(1), S1-S12. http://dx.doi.org/10.1093/jurban/79.suppl_1.S1

Greenspan, A. (2006). A framework for making a better decision. Research Review, 13(1), 1.

Haigh, F., \& Scott-Samuel, A. (2006). The Liverpool Citysafe Trailblazer Norris Green Health Impact Assessment, Final Report: IMPACT- International Health Impact Assessment Consortium. Liverpool, Division of Public Health University of Liverpool Whelan Building Quadrangle.

Hwang, C., \& Yoon, K. (1981). Multiple Attribute Decision Making: Methods and Applications, A State of the Art Survey, 1981. Sprinnger-Verlag, New York, NY.

Kihal-Talantikite, W., Padilla, C. M., Lalloué, B., Gelormini, M., Zmirou-Navier, D., \& Deguen, S. (2013). Green space, social inequalities and neonatal mortality in France. BMC pregnancy and childbirth, 13(1), 191. http://dx.doi.org/10.1186/1471-2393-13-191

Lang, J. (1994). Urban design: the American experience. New York., VNR, John Wiley \& Sons.

Maas, J., Verheij, R. A., Groenewegen, P. P., De Vries, S., \& Spreeuwenberg, P. (2006). Green space, urbanity, and health: How strong is the relation? Journal of Epidemiology and Community Health, 60(7), 587-592. http://dx.doi.org/10.1136/jech.2005.043125

Majizat, A., Ahmad, B. et al. (n.d.). Integrated Catchment Management of Urban Man-made Lake and WetlandsPutrajaya Experience. Putrajaya, Malaysia, Putrajaya Corporation.

Municipality of District 22. (2013). Chitgar man made lake. Tehran, Municipality of District 22.

Peters, N. (2002). Applying Community Health Impact Assessment to Rural Community Health Planning: Evaluation report. Canada, Antigonish Women's Resource Centre and the PATH Project Coordinating Committee.

Saaty, T. L. (1980). The Analytic Hierarchy Process. McGraw-Hill International. New York, NY, U.S.A.

Scotland Greenspace. (2008). Health Impact Assessment of Greenspace, A Guide. e. Scottish Natural Heritage 
and Institute of Occupational Medicin, Greenspace Scotland. Retrieved from www.greenspacescotland.org.uk/upload/File/Greenspace\% $\%$ 20HIA. pdf.

Singh, R., \& Bhatnagar, M. (2012). Urban lakes and wetlands: opportunities and challenges in Indian cities-Case study of Delhi. 12th edition of the World Wide Workshop for Young Environmental Scientists (WWW-YES-2012)-Urban waters: resource or risks?

Solar, O., \& Irwin, A. (2010). A conceptual framework for action on the social determinants of health.

Tsaur, R.-C. (2011). Decision risk analysis for an interval TOPSIS method. Applied Mathematics and Computation, 218(8), 4295-4304. http://dx.doi.org/10.1016/j.amc.2011.10.001

Tzeng, G.-H., \& Huang, J.-J. (2011). Multiple attribute decision making: Methods and applications. CRC Press.

University of California Berkeley Health Impact Group. (2007). MacArthur BART transit village health impact assessment. Retrieved from http://ehs.sph.berkeley.edu/hia/MBTV_DHIA_C0_ES_061107.pdf.

Vlahov, D., Freudenberg, N., Proietti, F., Ompad, D., Quinn, A., Nandi, V., \& Galea, S. (2007). Urban as a determinant of health. Journal of Urban Health, 84(1), 16-26. http://dx.doi.org/10.1007/s11524-007-9169-3

Woodward, B. (2008). Literature and Interview Project: Constructed Lakes in the Perth Metropolitan and South West Region. Australian, Department of Water Western Australian Local Government Association, Urban Development Institute of Australia.

Wright, K. (2003). Problems? What problems? We have none at all: Qualitative data collection for impact assessment. Journal of Microfinance/ESR Review, 5(1), 115-138.

Wu, F.-Y., \& Chuang, C.-C. (2013). The Optimal Relationship between Buyer and Seller Obtained Using TOPSIS Method. Journal of Advanced Management Science, $1(1)$. http://dx.doi.org/10.12720/joams.1.1.133-135

\section{Copyrights}

Copyright for this article is retained by the author(s), with first publication rights granted to the journal.

This is an open-access article distributed under the terms and conditions of the Creative Commons Attribution license (http://creativecommons.org/licenses/by/3.0/). 